\title{
Fenologia de Lafoensia pacari A.St.-Hil. (Lythraceae) em Barra do Garças, Mato Grosso, Brasil
}

\author{
SANTOS, L.W. ${ }^{1^{*}}$; COELHO, M.F.B ${ }^{2}$; PIRANI, F.R. ${ }^{3}$ \\ Instituto Universitário do Araguaia, Universidade Federal de Mato Grosso. Km 3,5 da Rodovia MT 100. Pontal do \\ Araguaia-MT, CEP: 78698-000, e-mail: *laerwan@cpd.ufmt.br ${ }^{2}$ Departamento de Ciências Vegetais, Universidade \\ Federal Rural do Semi-Árido. Km47 da BR 110. Bairro Pres. Costa e Silva. Mossoró-RN, CEP 59625-900 ${ }^{3}$ Mestranda \\ em Ecologia e Conservação da Biodiversidade, Instituto de Biociências, Universidade Federal de Mato Grosso. \\ Av. Fernando Correa da Costa, s/n. Cuiabá, MT, CEP 78625-900
}

\begin{abstract}
RESUMO: Lafoensia pacari A.St.-Hil. é uma espécie da flora do cerrado usada na medicina popular como anti-úlcera, antifúngica, antibactericida, anti-inflamatória, febrífuga, para emagrecimento e no tratamento de pneumonia, dores de estômago e coceiras. Estudou-se a fenologia de L. pacarino cerrado do Parque Estadual da "Serra Azul", região de Barra do GarçasMT (15ㄴ 51' 58" S e 52우 15' 37" W), à 645 m de altitude, durante o período de 24 meses. Verificouse que as fenofases são sazonais, com floração nos meses de abril a agosto, frutificação de junho a setembro, brotação no início da estação chuvosa de outubro a dezembro e queda de folhas de julho a setembro, no final da estação seca.
\end{abstract}

Palavras-chave: fenologia, plantas medicinais, mangava brava

\begin{abstract}
Phenology of Lafoensia pacari A.St.-Hil. (Lythraceae) in Barra do Garças, Mato Grosso State, Brazil. Lafoensia pacari is a species from the Brazilian cerrado used in folk medicine to control ulcers, fungal and bacterial diseases, inflammations, fevers, pneumonia, stomachaches, and itching, as well as to lose weight. L. pacari phenology was studied for 24 months in the cerrado at "Serra Azul" State Park, in the region of Barra do Garças, Mato Grosso State, Brazil (1551' 58' S and 520 15' 37' W), at $645 \mathrm{~m}$ altitude. Phenophases are seasonal, with flowering from April to August, fruiting from June to September, sprouting from October to December, during the beginning of the rainy season, and leaf fall from July to September, at the end of the dry season.
\end{abstract}

Key words: phenology, medicinal plants, "mangava-brava"

\section{INTRODUÇÃO}

A espécie Lafoensia pacari A.St.-Hil. (Lythraceae) é conhecida popularmente como: mangaba brava, pacari e dedal, entre outros nomes (Carvalho, 1994; Proença et al., 2000). Árvore de fitofisionomia de cerrado (s.s), cerradão, mata ciliar, mata seca (Mendonça et al.,1998; Silva Júnior, 2005) e florestas de altitude (Lorenzi, 1992), a L. pacari está presente no DF e nos seguintes estados brasileiros: BA, GO, MG, MA, MT, SP, MS, PR, SC, AP, PA e RS (Proença et al., 2000; Carvalho, 1994). Ocorre também em floresta semi-decídua e savana arbórea no Paraguai e Bolívia (Carvalho, 1994).

Essa espécie ocorre em muitos municípios de Mato Grosso (Felfili et al., 2002; Ratter et al., 1973;
Tonello, 1997), onde é usada para emagrecimento, tratamento de coceiras, feridas, dores de estômago (Tonello, 1997), úlceras (Tonello, 1997; Tamashiro Filho, 1999; Sartori, 1997; Solon, 1999; Silva Júnior, 2005) e como anti-inflamatória (Tonello, 1997; Rogério, 2002) e cicatrizante (Guarim Neto, 1987; Silva Júnior, 2005). Lima (1999) verificou que o extrato da raiz apresenta atividade antifúngica e bactericida, enquanto Souza et al. (2002) estudando extratos de folhas verificaram atividade antifúngica. Há registros da utilização dos frutos no tratamento de pneumonia, pelas populações indígenas Kaiowá e Guarani na reserva de Caarapó em Mato Grosso do Sul (Bueno et al., 2005). 
Foi constatada na espécie, presença de saponinas na casca do caule (Souza Júnior \& Rudolf, 1996; Tamashiro Filho, 1999; Solon, 1999), de esteróides e triterpenóides, fortemente positivo nas folhas e moderadamente positivo no cerne e na casca do caule, de flavonóides, negativo nas folhas, fracamente positivo no cerne e na casca do caule, de taninos, moderadamente positivo no cerne e nas folhas e moderada a fortemente positivo na casca do caule e de fenóis simples e ácidos fixos (Honda et al., 1990; Tamashiro Filho, 1999; Solon, 1999).

A demanda crescente, o intenso extrativismo das espécies medicinais e as constantes queimadas do Cerrado, vêm paulatinamente inserindo essa espécie na categoria de vulnerável, ou seja, aquela com probabilidade de passar à categoria de espécie em perigo de extinção (Fachim \& Guarim, 1995). O seu uso, com objetivos terapêuticos, tem reduzido o número de indivíduos no ambiente natural de sua ocorrência, devido ao caráter meramente extrativista dessa prática. A retirada da casca, para fins medicinais leva a planta à morte, causada pelo anelamento do caule (Tonello, 1997).

A fenologia estuda a ocorrência de eventos biológicos repetitivos e sua relação com o meio biótico e abiótico, buscando esclarecer a sazonalidade dos fenômenos biológicos (Morellato et al., 1990). Através de estudos fenológicos, torna-se possível conhecer a época de reprodução, a deciduidade e o ciclo de crescimento vegetativo das plantas, parâmetros que podem ser utilizados para o manejo adequado da flora (Ribeiro \& Castro, 1986).

A importância do estudo da fenologia de plantas do Cerrado, incluindo as medicinais, é evidenciada em trabalhos realizados por Ribeiro \& Castro (1986); Morellato (1989); Morellato et al. (1990); Gouveia \& Felfili (1998); Felfili et al. (1999); Batalha \& Mantovani (2000); Bencke \& Morellato (2002); Bulhão \& Figueiredo (2002) e Costa et al. (2004). Conhecer a fenologia é importante em programas de recuperação florestal ou qualquer outro que necessite de sementes de espécies nativas (Andreis et al., 2005). As informações sobre a floração e frutificação são fundamentais para a coleta de frutos e sementes para a propagação e posteriores trabalhos experimentais visando a identificação de fatores responsáveis pela ocorrência de fenofases. Segundo Martins et al. (1995), existem espécies onde a máxima concentração do princípio ativo é atingida a partir de determinada idade e/ou fase de desenvolvimento e geralmente as plantas que se encontram em floração e frutificação apresentam baixos teores de substâncias químicas nas folhas.

O presente trabalho teve por objetivo investigar o comportamento fenológico de $L$. pacari no cerrado do Parque Estadual da "Serra Azul" em Barra do Garças-MT, e correlacionar os padrões fenológicos com os fatores climáticos locais.

\section{MATERIALE MÉTODO}

O estudo fenológico foi realizado no Parque Estadual da Serra Azul - PESA, em Barra do Garças-

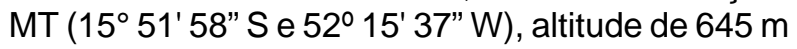
(Figura 1). A vegetação da área de estudo é caracterizada como cerrado sentido restrito

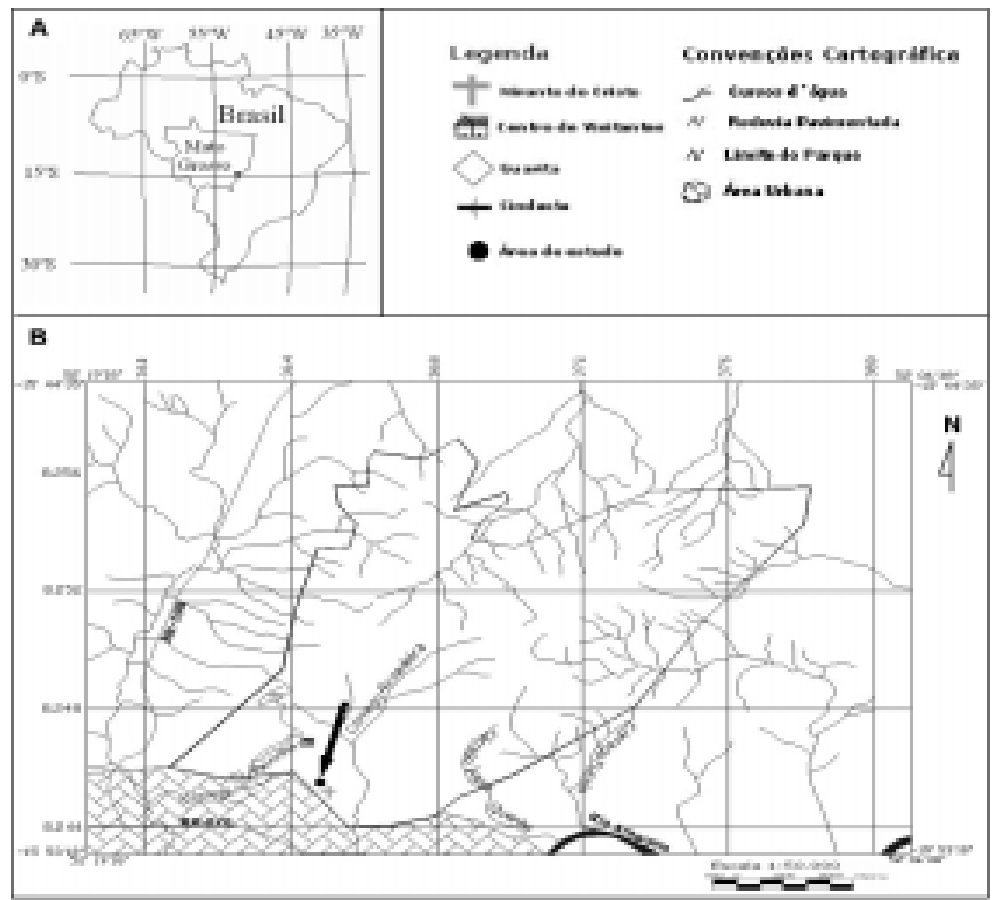

FIGURA 1. Localização do município de Barra do Garças, Mato Grosso (A) e da área de estudo no PESA, destacada pela seta (B). 
(Mendonça et al.,1998; Silva Júnior, 2005), e as espécies mais abundantes encontradas na área são Lafoensia pacari, Byrsonima pachyphyla, Davilla elliptica, Qualea grandiflora, Qualea parviflora e Kielmeyera coriaceae.

O clima da região é do tipo Aw, segundo a classificação de Koeppen (1948), que indica clima tropical chuvoso, com uma estação seca e fria (maiosetembro) e uma estação úmida e quente (outubroabril). A precipitação e as temperaturas máximas, médias e mínimas da região durante o período de estudo estão apresentadas na Figura 2. A precipitação durante o período de estudo foi de 1586,0 $\mathrm{mm}$ em
2004 e 1393, 1 mm em 2005; os valores mensais mais altos foram 483,7 mm em janeiro de 2004 e 390,1 $\mathrm{mm}$ em janeiro de 2005. Não houve precipitação nos meses de junho e agosto de 2004 e julho e agosto de 2005. As temperaturas mais altas foram registradas nos meses de setembro de 2004 e novembro de 2005, e as menores temperaturas foram registradas entre os meses de maio a agosto nos dois anos. Os dados climáticos foram coletados na estação meteorológica localizada em Aragarças-GO, a aproximadamente 5 $\mathrm{km}$ da área de estudo.

O acompanhamento fenológico de 29 indivíduos de $L$. pacari foi realizado mensalmente
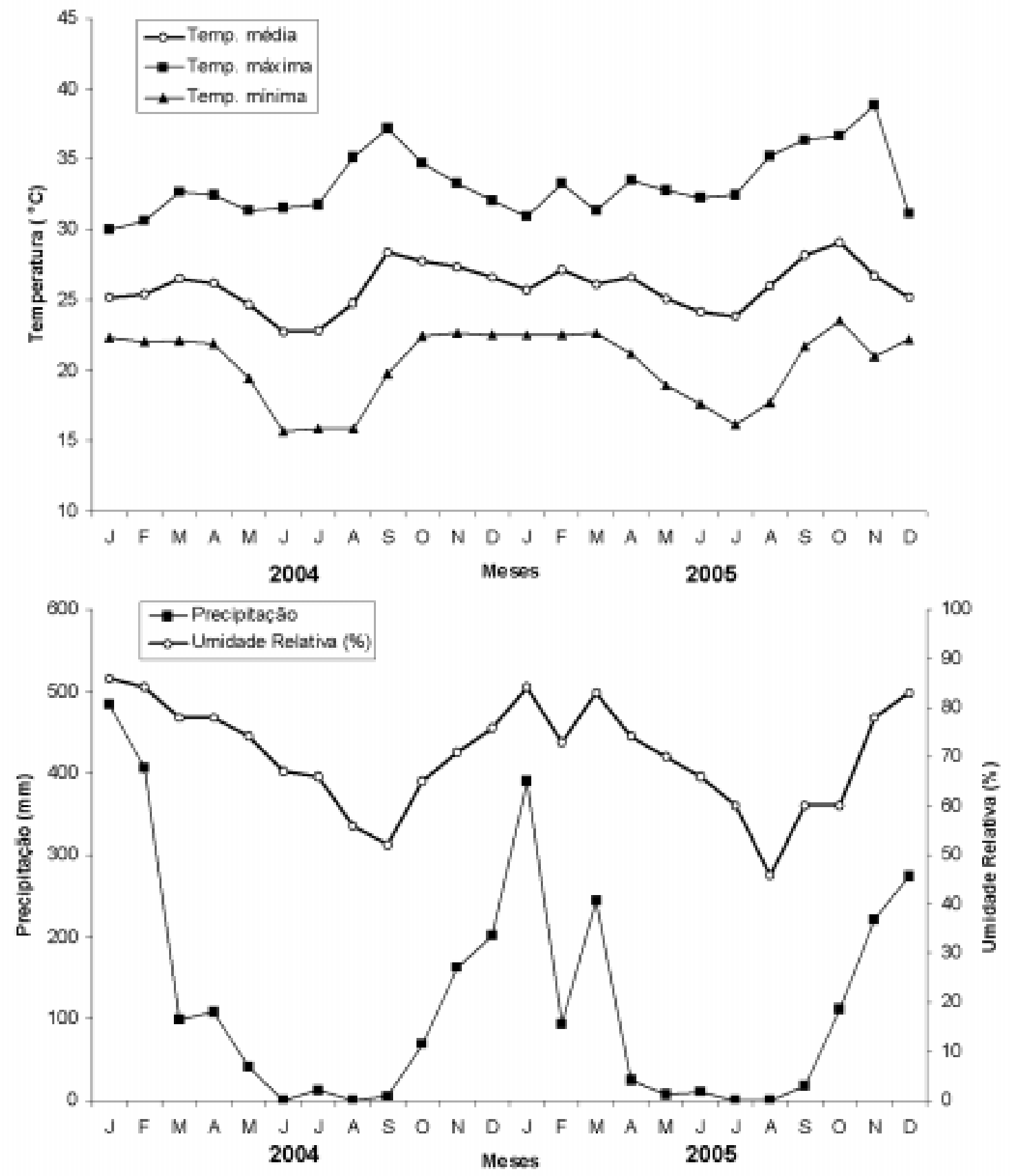

FIGURA 2. Temperaturas médias, máximas, mínimas, precipitação e umidade relativa do ar na região de Barra do Garças-MT, 2004/2005. Fonte: 10ํDisme/Min. Agricultura (Estação-83368). 
durante 24 meses, de janeiro/2004 a dezembro/2005, em uma área de $10.000 \mathrm{~m}^{2}$, dentro do Parque Estadual da Serra Azul. Foram observadas as fenofases queda foliar, brotamento, floração e frutificação (Morellato, 1989). Foi utilizado o índice de atividade ou percentual de indivíduos, método no qual é constatada somente a presença ou ausência da fenofase no indivíduo que está manifestando determinado evento fenológico (Bencke \& Morellato, 2002).

O teste de correlação de Spearman (Zar, 1999) foi aplicado para verificar se existe correlação entre os fatores climáticos (temperatura mínima e máxima e precipitação) e as fenofases observadas.

\section{RESULTADO E DISCUSSÃO}

A distribuição mensal, em percentagem, das plantas de $L$. pacari, indicou presença de flores nos meses de abril a julho de 2004 e junho a agosto de 2005, com maior intensidade da fenofase nos meses de maio de 2004 e agosto de 2005 (Figura 3). Tais resultados são similares aos encontrados por Tonello (1997), que verificou floração no final das chuvas, em abril, prolongando-se durante a seca, quando ocorre a frutificação, e por Carvalho (1994), que observou a floração de $L$. pacarinos meses de abril a junho em MT e de abril a agosto em MS.

Contudo a floração de L. pacari ocorre em diversos períodos em diferentes latitudes. No sul do país, Carvalho (1994) e Agostini \& Sazima (2003) verificaram a floração nessa espécie, de setembro a março em São Paulo, de outubro a janeiro em Santa Catarina, de outubro a março no Paraná e de novembro a janeiro no Rio Grande do Sul. Em Goiás, Proença et al. (2000) observaram a presença de flores em julho.

Verificou-se presença de frutos nos meses de junho a setembro de 2004 e de julho a agosto de 2005 (Figura 3). O amadurecimento dos frutos e dispersão das sementes ocorreu com maior intensidade nos meses de setembro de 2004 e agosto de 2005, coincidindo com a época de frutificação verificada por Carvalho (1994). Segundo este autor, os frutos amadurecem em agosto, no Distrito Federal; em setembro, em Mato Grosso; de fevereiro a junho, no Rio Grande do Sul; de abril a outubro, no Paraná e em São Paulo.

Gouveia \& Felfili (1998) afirmam que o amadurecimento dos frutos das espécies mais abundantes no Cerrado, no final da estação seca, parece ser uma vantagem competitiva para o êxito dessas espécies. Entretanto, a frutificação de $L$. pacari durante a seca, período de maior freqüência de incêndios no Cerrado, facilita a queima de suas sementes, as quais não possuem um envoltório protetor, o que pode ser considerado como fator limitante na propagação dessa espécie (Tonello, 1997).

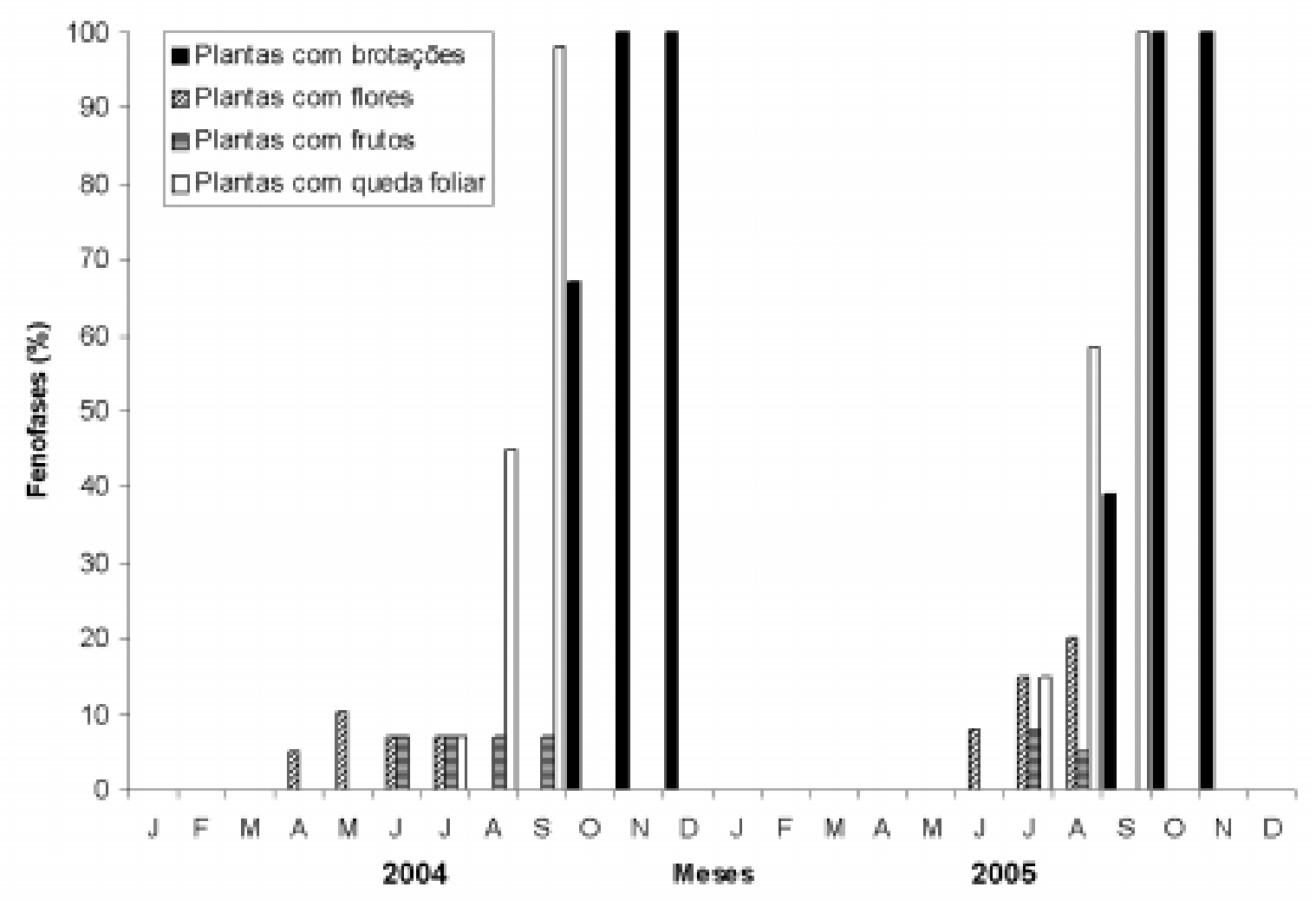

FIGURA 3. Distribuição mensal média, em percentagem das diferentes fenofases de plantas de L. pacari, ao longo de 2004 e 2005 
A abscisão das folhas iniciou-se no mês de julho de cada ano e apresentou maior intensidade nos meses de setembro de 2004 e 2005 em 98 e $100 \%$, respectivamente, com queda total das folhas (Figura 3), seguindo um padrão similar ao encontrado por Pott \& Pott (1994) e Silva Júnior (2005), que observaram a abscisão foliar na espécie, de julho a setembro. Segundo Tonello (1997), os primórdios foliares surgem entre agosto e novembro, em Mato Grosso.

A floração, a frutificação e a abscisão foliar são sazonais e coincidem com o período de seca: abril a outubro (Figuras 2 e 3). A sazonalidade em vegetações do Cerrado exerce grande influência nos eventos fenológicos, com os meses de maio a setembro correspondendo à época seca e os de outubro a abril, à das chuvas, sendo essas estações as de menor e maior umidade relativa e temperatura, respectivamente (Felfili et al.,1999).

O brotamento ocorreu de outubro a dezembro em 2004 e de setembro a novembro em 2005, com maior intensidade no início do período chuvoso (Figura 3). No entanto, resultados diferentes foram encontrados por outros autores. Segundo Tonello (1997), os primórdios foliares surgem entre agosto e novembro e a abscisão foliar inicia-se simultaneamente ao aparecimento dos primeiros frutos na população e, segundo Pott \& Pott (1994) e Silva Júnior (2005), o brotamento ocorre de junho a setembro.

A floração mostrou correlação negativa com a precipitação $(r=-0,57$ e $P=0,0)$ e com a temperatura mínima $(r=-0,69$ e $P=0,0)$. A floração na seca parece ser o padrão mais comum da vegetação arbórea do Cerrado e de savanas. Este padrão tem sido tomado como evidência de que a floração seja induzida por reidratação ocasionada pela redução da transpiração e utilização da água residual (Borchert, 1994). A frutificação esteve correlacionada inversamente com a temperatura mínima $(r=-0,75$ e $P=0,0)$ e com a precipitação $(r=-0,74$ e $P=0,0)$ (Tabela 1). Mantovani \& Martins (1988), estudando variações fenológicas das espécies do cerrado da Reserva de Moji Guaçu-SP encontraram que a maioria das espécies anemocóricas frutificou na estação seca, semelhante ao padrão apresentado por L. pacari.

A queda foliar mostrou correlação negativa com a temperatura mínima $(r=-0,46$ e $P=0,03)$ e com a precipitação $(r=-0,48$ e $P=0,03)$ (Tabela 1$)$. A correlação entre queda foliar e diminuição da pluviosidade encontrado para $L$. pacari sugere este fator como desencadeador desta fenofase. Segundo Morellato (1991) a deficiência hídrica ou a sua associação à temperatura poderiam determinar a intensidade e duração da perda de folhas. O brotamento apresentou correlação com a temperatura mínima $(r=0,53$ e $P=0,01)$ e com a temperatura máxima $(r=0,53$ e $P=0,04)$ (Tabela 1). Morellato et al. (1989) sugerem que a variação sazonal da temperatura pode induzir o brotamento em árvores tropicais.

TABELA 1. Índices de correlação de Spearman (r) entre as fenofases e as variáveis climáticas.

$$
\mathrm{P}=\text { probabilidade }
$$

\section{CONCLUSÃO}

Concluiu-se neste estudo que as fenofases das plantas de L. pacari, observadas em Barra do Garças-MT, são sazonais, com floração nos meses de abril a agosto, frutificação de junho a setembro, queda de folhas de julho a setembro, no final da estação seca, e brotamento de setembro a dezembro.

\section{REFERÊNCIA}

AGOSTINI, K.; SAZIMA, M. Plantas ornamentais e seus recursos para abelhas no campus da Universidade Estadual de Campinas, Estado de São Paulo, Brasil. Bragantia, v.62, n.3, p.335-43, 2003.

ANDREIS, C. et al. Estudo fenológico em três fases sucessionais de uma floresta estacional decidual no município de Santa Tereza, RS, Brasil. Revista Árvore, v.29, n.1, p.55-63, 2005.

BATALHA, M.A.; MANTOVANI, W. Reproductive phenological patterns of cerrado plant species at the Pé-de-Gigante reserve (Santa Rita do Passa Quatro, SP, Brazil): a comparison between the herbaceous and wood floras. Revista Brasileira de Biologia, v.60, n.1, p.12945, 2000.

BENCKE, C.S.C.; MORELLATO, L.P.C. Comparação de dois métodos de avaliação da fenologia de plantas, sua interpretação e representação. Revista Brasileira de Botânica, v.25, n.3, p.269-75, 2002.

BORCHERT, R. Soil and stem water storage determine phenology and distribution of tropical dry forest trees. Ecology, v.75, n.5, p.1437-49, 1994.

BUENO, N.R. et al. Medicinal plants used by the Kaiowá

Rev. Bras. Pl. Med., Botucatu, v.11, n.1, p.12-17, 2009. 
and Guarani indigenous populations in the Caarapó Reserve, Mato Grosso do Sul, Brazil. Acta Botanica Brasilica, v.19, n.1, p.39-44, 2005.

BULHÃO, C.F.; FIGUEIREDO, P.S. Fenologia de leguminosas arbóreas em uma área de cerrado marginal no nordeste do Maranhão. Revista Brasileira de Botânica, v.2, n.3, p.361-9, 2002.

CARVALHO, P.E.R. Espécies florestais brasileiras: recomendações silviculturais, potencialidade e uso da madeira. Brasilia: EMBRAPA, CNPF. Colombo,1994. 640p. Disponível em <http://www.cnpf.embrapa.br/ pauloernani/temp/index_especies.htm>. Acesso em: 22 ago. 2005.

COSTA, I. R.; ARAÚJO, F.S.; LIMA-VERDE, L.W. Flora e aspectos auto-ecológicos de um encrave de cerrado na chapada do Araripe, Nordeste do Brasil. Acta Botanica Brasilica, v.18, n.4, p.759-70, 2004.

FACHIM, E.; GUARIM, V.L.M.S. Conservação da biodiversidade: espécies da flora de Mato Grosso. Acta Botanica Brasilica, v.9, n.2, p.281-302, 1995.

FELFILI, J.M. et al. Estudo fenológico de Stryphnodendron adstringens (Mart.) Coville no cerrado sensu stricto da Fazenda Água Limpa no Distrito Federal, Brasil. Revista Brasileira de Botânica, v.22, n.1, p.83-90, 1999.

FELFILI, J.M. et al. Composição florística e fitossociologia do cerrado sentido restrito no município de Água BoaMT. Acta Botanica Brasilica, v.16, n.1, p.103-12, 2002. GUARIM NETO, G. Plantas utilizadas na medicina popular no estado de Mato Grosso. Brasilia: CNPq, 1987. 58p.

GOUVEIA, G.P.; FELFILI, J.M. Fenologia de comunidades do cerrado e de mata de galeria no Brasil Central. Revista Árvore, v.22, n.4, p.443- 50, 1998.

HONDA, N.K. et al. Estudo químico de plantas de Mato Grosso do Sul I: triagem fitoquímica. Revista Científica Cultural, v.1, n.5, p.37-46, 1990.

KOEPPEN, W. Climatologia: com um estudio de los climas de la tierra. México: Fondo de Cultura Econômica, 1948. 312p.

LIMA, M.R.F. Estudos de plantas e compostos naturais e atividades moluscicida, antimicrobiana e frente a Artemia salina. 1999. 134p. Dissertação (Mestrado em Química e Biotecnologia) - Instituto de Química e Biotecnologia, Universidade Federal de Alagoas, Maceió. LORENZI, H. Árvores brasileiras: manual de identificação e cultivo de plantas nativas do Brasil. Nova Odessa: Plantarum, 1992. 352p.

MANTOVANI, W.; MARTINS, F.R. Variações fenológicas das espécies do cerrado da Reserva Biológica de Moji Guaçu, Estado de São Paulo. Revista Brasileira de Botânica, v.11, n.1/2, p.101-12, 1988.

MARTINS, E.R. et al. Plantas medicinais. Viçosa: UFV, 1995. 220p.

MENDONÇA, R.C. et al. Flora vascular do cerrado. In: SANO, S.M.; ALMEIDA, S.P. (Eds.). Cerrado: ambiente e flora. Planaltina: EMBRAPA-CPAC, 1998. p.289-556.

MORELLATO, L.P.C. et al. Estudo comparativo da fenologia de espécies arbóreas de floresta de altitude e floresta mesófila semidecídua na Serra do Japi, Jundiaí, São Paulo. Revista Brasileira de Botânica, v.12, n.1/2, p.85-98, 1989.

MORELLATO, L.P.C. et al. Estratégias fenológicas de espécies arbóreas em floresta de altitude na Serra do Japi, Jundiaí, São Paulo. Revista Brasileira de Biologia, v.50, n.1, p.149-62, 1990.

MORELLATO, L.P.C. Estudo da fenologia de arvores, arbustos e lianas de uma floresta semidecídua no sudeste do Brasil. 1991. 176p. Tese (Doutorado em Ecologia) - Instituto de Biologia, Universidade Estadual de Campinas, Campinas.

POTT, A.; POTT, V. Plantas do pantanal. Corumbá: EMBRAPA, 1994. 320p.

PROENÇA, C.; OLIVEIRA, R.S.; SILVA, A.P. Flores e frutos do cerrado. Brasilia: EdUnB, São Paulo: Imprensa oficial, 2000. 226p.

RATTER, J.A. et al. Observations on the vegetation of northeastern, Mato Grosso: I the woody vegetation types of the Xavantina - Cachimbo expedition area. Philosophical Transaction for the Royal Society, v.266, n.880, p.449-92, 1973.

RIBEIRO, J.R.; CASTRO, L.H.R. Método quantitativo para avaliar características fenológicas em árvores. Revista Brasileira de Botânica, v.9, n.1, p.7-11, 1986.

ROGÉRIO, A.P. Estudo da atividade antiinflamatória do extrato etanólico de Lafoensia pacari Jaume St. Hilaire (Lythraceae). 2002. 88p. Dissertação (Mestrado em Ciências Farmacêuticas) - Faculdade de Ciências Farmacêuticas, Universidade de São Paulo, Ribeirão Preto. SARTORI, N.T. Triagem de plantas medicinais popularmente utilizadas como anti-úlcera em Mato Grosso e avaliação do efeito anti-úlcera da fração diclorometânica (DCM2) de Calophyllum brasiliense Camb. (guanandi). 1997. 121p. Dissertação (Mestrado em Saude e Ambiente) - Faculdade de Ciências Médicas, Universidade Federal de Mato Grosso, Cuiabá.

SILVA JÚNIOR, M.C. 100 Árvores do cerrado: guia de campo. Brasilia: Ed. Rede de sementes do cerrado, 2005. 278p.

SOLON, S. Alguns aspectos químicos da entrecasca do caule de Lafoensia pacari St. Hil. (Mangava brava, Lytrhraceae). 1999. 147p. Dissertação (Mestrado em Saúde e Ambiente) - Faculdade de Ciências Médicas, Universidade Federal de Mato Grosso, Cuiabá.

SOUZA JÚNIOR, P.T.; RUDOLF, S. Estudo químico preliminar dos constituíntes farmacologicamente ativos da casca do caule da Lafoensia pacari St. Hil. (mangava brava). In: ENCONTRO DE INICIAÇÃO CIENTÍFICA, 4., Resumos... Cuiabá: UFMT.MCT/CNPq, 1996. p.65.

SOUZA, L.K.H. et al. Antifungal properties of Brazilian cerrado plants. Brazilian Journal of Microbiology, v.33, n.3, p.247-9, 2002.

TAMASHIRO FILHO, P. Avaliação da atividade antiúlcera do extrato bruto metanólico de Lafoensia pacariSt.Hil. (mangava brava). 1999. 128p. Dissertação (Mestrado em Saúde Pública e Ambiente) - Faculdade de Ciências Médicas, Universidade Federal de Mato Grosso, Cuiabá. TONELLO, V.M. Estrutura de populações de Lafoensia pacariSt. Hil. e dados etnobotânicos e fenológicos em Nossa Senhora do Livramento, Mato Grosso. 1997. 94p. Dissertação (Mestrado em Ecologia e Conservação da Biodiversidade) - Instituto de Biociências, Universidade Federal de Mato Grosso, Cuiabá.

ZAR, J.H. Biostatistical analysis. 4.ed. New Jersey: Prentice Hall, 1999. 929p. 